\title{
Effect of Body Mass Index on Survival in Patients with Epithelial Ovarian Cancer
}

\author{
Suzy F. Gohar ${ }^{1}$, Ashraf E. Abdel-Ghany ${ }^{1}$, Shaimaa S. Soliman ${ }^{2}$ \\ ${ }^{1}$ Department of Clinical Oncology, Faculty of Medicine, Menoufia University, Shibin Elkom, Egypt, ${ }^{2}$ Department \\ of Public Health and Community Medicine, Faculty of Medicine, Menoufia University, Shibin Elkom, Egypt
}

Introduction: Higher body mass index (BMI) is an independent and well-established prognostic factor in hormonerelated cancers, such as breast and endometrial cancer. As a hormone-dependent cancer, ovarian cancer, however, has been linked inconsistently to obesity.

Aim: This work aimed to assess the association between BMI and ovarian cancer survival.

Methods: This retrospective study included 66 patients who were treated for epithelial ovarian cancer from January 2011 to April 2014. Clinical and epidemiological characteristics of patients were collected.

Time to progression and overall survival were calculated. BMI was calculated using the formula weight in kilograms divided by the square of the height in meters, and categorized according to World Health Organization classification.

Results: BMI indicated underweight in 3 patients (4.5\%), healthy weight range in 11 (16.7\%), pre-obesity in 17 (25.8\%), obesity class I in 13 (19.7\%), obesity class II in 8 (12.1\%) and obesity class III in 14 (21.2\%). BMI did not associate significantly with disease stage $(\mathrm{p}=0.54)$, pathology $(\mathrm{p}=0.82)$, initial CA-125 level $(\mathrm{p}=0.61)$, platinum sensitivity $(\mathrm{p}=0.27)$, time to progression $(\mathrm{p}=0.58)$ or overall survival $(\mathrm{p}=0.87)$.

Conclusion: Our results suggest prevalence of obesity (relatively high) among Egyptian patients with epithelial ovarian cancer. Noteworthy, BMI had no significant association with disease stage, platinum sensitivity, time-to-progression or overall survival in the studied group.

Key words: Ovarian Carcinoma, Body mass index, Survival

Corresponding Author: Suzy Gohar, M.D. Department of Clinical Oncology, Faculty of Medicine, Menoufia University, Shibin Elkom, Egypt, E-mail: suzygohar@ymail.com

Submitted: 27-August-2016, Revised: 6-October-2016, Accepted: 6-November-2016

\section{INTRODUCTION}

Ovarian cancer is the sixth most commonly diagnosed gynecologic tumor and constitutes a leading cause of mortality within this group of tumors ${ }^{1}$. This is because of its typically insidious onset and late diagnosis. Subsequently, only about $40 \%$ of women with ovarian cancer can be still alive more than 5 years post-diagnosis ${ }^{2}$.

This poor survival is largely attributable to the fact that most cases of ovarian cancer in developing countries are diagnosed with advanced stage ${ }^{3}$.

In Egypt, ovarian cancer represents $4.7 \%$ of all female cancers. It is ranked as the third and comprises $40.7 \%$ of all gynecologic cancers ${ }^{4}$.

Risk factors such as obesity, commonly measured by body mass index (BMI), have been found to associate with poorer survival in a number of cancers including breast, prostate, and colorectal cancer ${ }^{5}$.

Relation between obesity and epithelial ovarian cancer is still unclear. It is hypothesized that elevated androgen level mediated by obesity in the presence of certain androgen receptor polymorphisms might promote aggressive epithelial ovarian cancer biology ${ }^{6}$.

This study aimed to assess the association between BMI and survival in Egyptian patients with epithelial ovarian cancer.

\section{METHODS}

This retrospective study was carried out on patients with epithelial ovarian cancer at the Oncology Department, Faculty of Medicine, Menoufia University. .

In the study period, from January 2011 to April 2014, a total of 87 patients were enrolled, but the clinical data completed only for $66(76 \%)$ patients.

The collected data include patients' personal and clinical characteristics (age, performance status, weight, height, co-morbidities, parity and surgical interference), in addition to the disease characteristics, baseline investigations, treatment course, time to progression (TTP) and overall survival (OS).

Standing height was determined without shoes using Harpenden stadiometer (to the nearest $0.1 \mathrm{Cm}$ ).. Weight was measured using a digital scale (to the nearest 0.1 $\mathrm{Kg}$ ) wearing light clothing and without shoes. BMI was calculated using the formula weight (in kilograms) divided by height (in meters) squared.

The World Health Organization classification of $\mathrm{BMI}^{7}$ was used to classify patients as shown in Table 1 .

Results were collected, tabulated and statistically analyzed by an IBM compatible personal computer with SPSS statistical package version 20 (IBM SPSS statistics for Windows, version 20.0, Armnok, NY: IBM Corp.). 
Descriptive statistics were expressed in number (No), percentage (\%), mean $(\overline{\mathbf{x}})$ and standard deviation (SD). For quantitative variables, Student's $t$-test was used for comparison between two groups of normally distributed data, while Mann-Whitney's test was used in the case of abnormal distribution. ANOVA test was used for comparison of quantitative variables between more than two groups of normally distributed data with LSD test as post Hoc test; while Kruskal Wallis test was used for comparison of quantitative variables between more than two groups of abnormally distributed data with Tamhane's test as a post hoc test. The correlation between two continuous variables was tested using Pearson correlation for normally-distributed data and Spearman correlation for abnormally-distributed data. Chi-square test $\left(\chi^{2}\right)$ was used to study association between qualitative variables. Whenever any of the expected cells were less than five, Fischer's exact test was used. Kaplan-Meier method was used for survival analysis and Log rank was used to test the significance of difference in survival between groups.

\section{RESULTS}

The included 66 patients' age ranged from 23 to 73 years and their BMI ranged from 17.6 to 48.1 . More than half of patients were obese (BMI $\geq 30$ ). Patients' characteristics are shown in Table 2.

Disease characteristics are shown in Table 3. Serous adenocarcinoma was the commonest pathology among the studied group $(80.3 \%)$. Fifty two patients $(78.8 \%)$ had elevated tumor marker CA-125 at presentation.

Table 4 shows the relationship between some of the studied variables and BMI. The average BMI did not differ significantly according to any of these variables.

Thirty seven patients (56\%) were followed up until death. The estimated median OS of the whole group of patients was 47 months (95\%CI: 37.25 - 56.74).

Table 5 shows the relation between OS and some of the studied variables. Overall survival was significantly better in patients with platinum sensitive tumors, those who underwent surgery (at presentation or interval) and those with normal CA-125 level at presentation.

On comparing OS and TTP of patients with BMI $\leq 25$ and patients with $\mathrm{BMI}>25$, no statistically significant difference was obtained between the two groups ( $p$-value $=0.93$ for both). Kaplan Meier curve for OS and PFS in these two groups are shown in figures 1 and 2.

The estimated median OS of patients with a BMI $\leq 25$ was 50 months (95\%CI: $19.75-80.24)$ while that of those with a BMI $>25$ was 42 months (95\% CI: $33.51-50.48)$.

The estimated median TTP of patients with a BMI $\leq 25$ was 18 months ( $95 \%$ CI: $0-41.83)$ while that of those with a BMI >25 was 23 months ( $95 \%$ CI: $15.24-30.75)$.

There was no statistically significant difference between the different categories of BMI as regards to OS and TTP as shown in Table 6. Kaplan Meier curves showing OS and TTP in different BMI categories are shown in figures 3 and 4.

Table 1: The International Classification of adult underweight, overweight and obesity according to $\mathrm{BMI}^{7}$.

\begin{tabular}{lr}
\hline Classification & BMI $\left(\mathbf{k g} / \mathbf{m}^{2}\right)$ \\
\hline Underweight & $<18.5$ \\
\hline Normal range & $18.5-24.99$ \\
\hline Overweight & \\
\hline Pre-obese & $25-29.99$ \\
\hline Obese & $30-34.99$ \\
\hline Obese class I & $35-39.99$ \\
\hline Obese class II & $\geq 40$ \\
\hline Obese class III
\end{tabular}

Table 2: Patients' characteristics.

\begin{tabular}{|c|c|c|}
\hline & Mean \pm SD, & Range \\
\hline Age (years) & $52.19 \pm 10.9$ & $23-73$ \\
\hline Weight (kg) & $78.27 \pm 20.16$ & $39-125$ \\
\hline Height (cm) & $156.93 \pm 6.36$ & $145-178$ \\
\hline \multirow[t]{2}{*}{ Body mass index } & $31.75 \pm 7.93$ & $17.6-48.1$ \\
\hline & No. & $\%$ \\
\hline \multicolumn{3}{|l|}{ Parity } \\
\hline Multipara & 53 & 80.3 \\
\hline Nullipara & 13 & 19.7 \\
\hline \multicolumn{3}{|l|}{ Co-morbidities } \\
\hline Hypertension & 10 & 15.2 \\
\hline Diabetes & 5 & 7.6 \\
\hline Diabetes \& hypertension & 3 & 4.5 \\
\hline None & 48 & 72.7 \\
\hline \multicolumn{3}{|l|}{ ECOG performance status } \\
\hline 0 & 22 & 33.3 \\
\hline 1 & 33 & 50 \\
\hline 2 & 10 & 15.2 \\
\hline 3 & 1 & 1.5 \\
\hline \multicolumn{3}{|l|}{ Time of surgery } \\
\hline Initial & 35 & 53 \\
\hline Interval & 16 & 24.2 \\
\hline None & 15 & 27.7 \\
\hline \multicolumn{3}{|l|}{ Result of surgery } \\
\hline Optimal & 14 & 21.2 \\
\hline Suboptimal & 37 & 56.1 \\
\hline \multicolumn{3}{|l|}{ Body mass index groups } \\
\hline Underweight & 3 & 4.5 \\
\hline Normal range & 11 & 16.7 \\
\hline Pre-obese & 17 & 25.8 \\
\hline Obesity class I & 13 & 19.7 \\
\hline Obesity class II & 8 & 12.1 \\
\hline Obesity class III & 14 & 21.2 \\
\hline
\end{tabular}

ECOG: Eastern Cooperative Oncology Group 
Table 3: Disease characteristics.

\begin{tabular}{llll}
\hline & No. & $\%$ \\
\hline Laterality & & 50 \\
\hline Unilateral & 33 & 50 \\
\hline Bilateral & 33 & 22.7 \\
\hline Stage & 15 & 10.6 \\
\hline I & 7 & 36.4 \\
\hline II & 24 & 30.3 \\
\hline III & 20 & 72.7 \\
\hline IV & & 27.3 \\
\hline Sensitive & 48 & 80.3 \\
\hline Resistant & 18 & 9.1 \\
\hline Pathology subtype & & 10.6 \\
\hline Serous adenocarcinoma & 53 & \\
\hline Mucinous adenocarcinoma & 6 & 21.2 \\
\hline Endometroid & 7 & 78.8 \\
\hline CA-125 initial level & & \\
\hline Normal & 14 & \\
\hline Elevated & 52 & \\
\hline
\end{tabular}

Table 4: Comparison between different aspects of characteristics regarding BMI.

\begin{tabular}{|c|c|c|}
\hline & $\begin{array}{c}\text { BMI } \\
(\text { Mean } \pm \text { SD) }\end{array}$ & P-value \\
\hline \multicolumn{3}{|l|}{ Stage } \\
\hline $\mathrm{I}$ & $32.55 \pm 7.37$ & \multirow[t]{4}{*}{0.54} \\
\hline II & $30.48 \pm 6.42$ & \\
\hline III & $30.90 \pm 7.45$ & \\
\hline IV & $32.61 \pm 0 / 59$ & \\
\hline \multicolumn{3}{|l|}{ Platinum Sensitivity } \\
\hline Sensitive & $32.40 \pm 7.58$ & \multirow[t]{2}{*}{0.27} \\
\hline Resistant & $30.01 \pm 8.78$ & \\
\hline \multicolumn{3}{|l|}{ Pathological subtypes } \\
\hline Serous adenocarcinoma & $31.99 \pm 7.59$ & \multirow[t]{3}{*}{0.82} \\
\hline Mucinous adenocarcinoma & $31.23 \pm 6.36$ & \\
\hline Endometroid & $30.35 \pm 12.02$ & \\
\hline \multicolumn{3}{|l|}{ CA-125 initial level } \\
\hline Normal & $32.93 \pm 7.92$ & \multirow[t]{2}{*}{0.61} \\
\hline Elevated & $31.43 \pm 7.98$ & \\
\hline \multicolumn{3}{|l|}{ Parity } \\
\hline Multipara & $32.72 \pm 7.82$ & \multirow[t]{2}{*}{0.06} \\
\hline Nullipara & $28.18 \pm 7.38$ & \\
\hline \multicolumn{3}{|l|}{ Co-morbidities } \\
\hline Hypertension & $33.11 \pm 5.94$ & \multirow[t]{4}{*}{0.09} \\
\hline Diabetes & $40.12 \pm 7.65$ & \\
\hline Hypertension \& diabetes & $32.86 \pm 8.28$ & \\
\hline None & $30.53 \pm 7.93$ & \\
\hline \multicolumn{3}{|l|}{ Time of surgery } \\
\hline Initial & $32.10 \pm 1.49$ & \multirow[t]{3}{*}{0.75} \\
\hline Interval & $30.46 \pm 5.55$ & \\
\hline None & $32.30 \pm 8.09$ & \\
\hline
\end{tabular}


Table 5: Overall survival (OS) according to different risk factors.

\begin{tabular}{|c|c|c|c|c|}
\hline & $\begin{array}{c}\text { Estimated median } \\
\text { OS } \\
\end{array}$ & SE & $95 \%$ CI & P-value \\
\hline \multicolumn{5}{|l|}{ Platinum Sensitivity } \\
\hline Sensitive & 50 & 5.82 & $38.59-61.4$ & \multirow[t]{2}{*}{$<0.001$} \\
\hline Resistant & 11 & 3.18 & $4.76-17.23$ & \\
\hline \multicolumn{5}{|l|}{ Pathology } \\
\hline Serous adenocarcinoma & 39 & 4.30 & $30.57-47.42$ & \multirow[t]{3}{*}{0.09} \\
\hline Mucinous adenocarcinoma & - & - & - & \\
\hline Endometroid & 59 & 9.41 & $40.53-77.46$ & \\
\hline \multicolumn{5}{|l|}{ Time of surgery } \\
\hline Initial & 49 & 5.15 & $38.9-59.1$ & \multirow[t]{3}{*}{$<0.001$} \\
\hline Interval & 56 & 9.87 & $36.65-75.34$ & \\
\hline None & 11 & 1.93 & $7.21-14.78$ & \\
\hline \multicolumn{5}{|l|}{ Stage } \\
\hline $\mathrm{I}$ & 71 & 28.57 & $15-127$ & \multirow[t]{4}{*}{0.60} \\
\hline II & 42 & 11.08 & $20.27-63.72$ & \\
\hline III & 41 & 7.45 & $26.38-55.61$ & \\
\hline IV & 49 & 8.38 & $32.55-65.44$ & \\
\hline \multicolumn{5}{|l|}{ Ca-125 initial level } \\
\hline Normal & 71 & 15.56 & $40.48-101.51$ & \multirow[t]{2}{*}{0.01} \\
\hline Elevated & 41 & 3.25 & $34.62-47.37$ & \\
\hline
\end{tabular}

Table 6: Estimated overall survival and time to progression according to BMI.

\begin{tabular}{|c|c|c|c|c|c|c|c|c|}
\hline & \multicolumn{4}{|c|}{ Overall survival (months) } & \multicolumn{4}{|c|}{ Time to progression (months) } \\
\hline & Median & SE & $95 \%$ CI & P-value & Median & SE & $95 \%$ CI & P-value \\
\hline Underweight & 59 & 0 & --- & 0.87 & 8 & 1.63 & $4.79-11.2$ & 0.58 \\
\hline Normal range & 50 & 26 & $31.61-100.96$ & & 38 & 17.94 & $2.82-73.18$ & \\
\hline Pre-obese & 43 & 5.8 & $11.18-54.38$ & & 18 & 6.86 & $4.55-31.44$ & \\
\hline Obesity class I & 47 & 18.27 & $0-82.81$ & & 23 & 4.95 & $13.28-32.71$ & \\
\hline Obesity class II & 69 & 43.22 & $22.68-153.71$ & & 29 & 15.71 & $0-59.79$ & \\
\hline Obesity class III & 39 & 8.32 & $22.68-55.31$ & & 19 & 7.48 & $4.33-33.66$ & \\
\hline
\end{tabular}

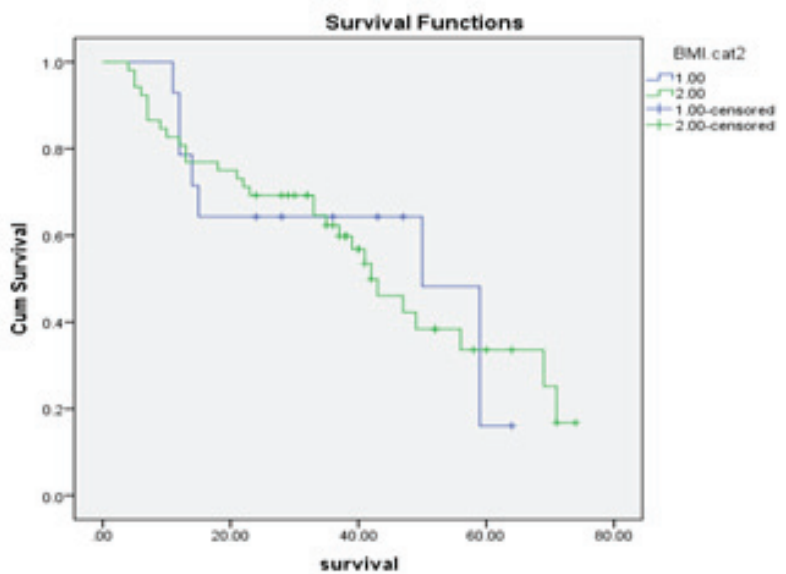

Figure. 1: Kaplan Meier curves showing overall survival of patients with $\mathrm{BMI} \leq 25$ and those with $\mathrm{BMI}>25$

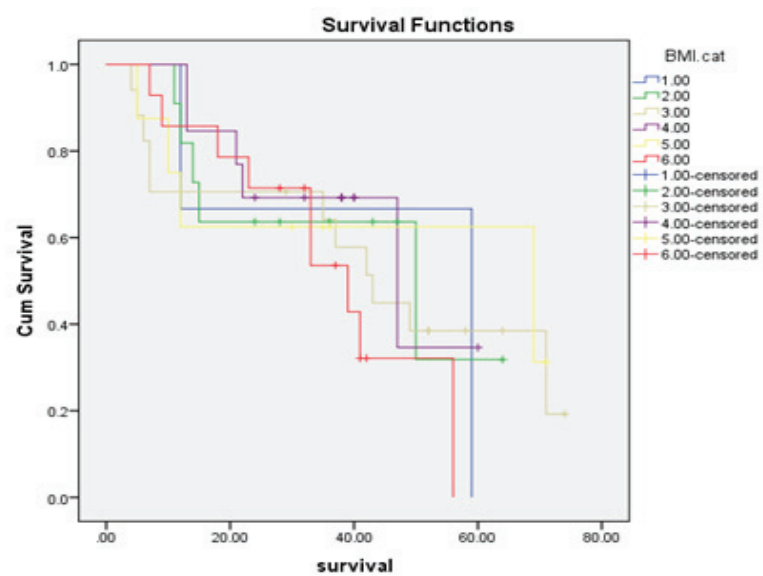

Figure. 3: Kaplan Meier curves showing overall survival of different BMI categories 


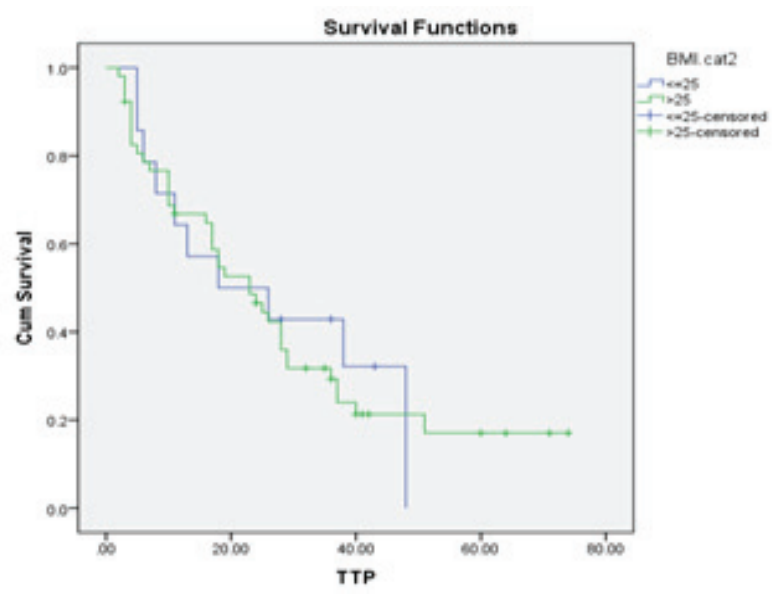

Figure. 2: Kaplan Meier curves showing time to progression of patients with $\mathrm{BMI} \leq 25$ and those with $\mathrm{BMI}>25$

\section{DISCUSSION}

Obesity is an established risk factor for ovarian cancer, and is associated with poor outcome in several tumors like breast cancer and colorectal cancer. However, the relation between obesity and ovarian cancer survival is less clear.

In this retrospective study, we found no statistically significant effect of being obese $(\leq 25 \mathrm{BMI})$ or non obese $(\mathrm{BMI}>25)$ on OS in ovarian cancer patients. Alike, Matthews et $a l^{8}$ found no difference in survival between patients with normal or abnormal BMI provided that complete surgical resection was done. Subsequently, he concluded that BMI was not the main issue; it was the possibility of resection. Also Zhang et al ${ }^{9}$ found no statistically significant relation between BMI at diagnosis of ovarian cancer and patients' OS.

Our results are consistent with previous studies, whereas no association noted between ovarian cancer survival and being pre-obese or obese e $^{8-12}$.

Till now, the adverse effect of obesity on ovarian cancer survival remains equivocal for BMI measured at the time of diagnosis, where Bae et $a^{13}$ reported that BMI does not influence the survival of advanced stage patients except in underweight patients, which may be related to cancer related cachexia.

Noteworthy, Tyler et al studied the impact of BMI on survival of younger patients with epithelial ovarian cancer and also found no association ${ }^{15}$.

On the contrary, a recent large study which included the original data of 12,390 patients with ovarian carcinoma from 21 studies revealed that high BMI associated with an adverse effect on survival ${ }^{16}$. Such discrepancy in results may be attributed to the difference in sample size.

In our current study, no significant correlation obtained between BMI and TTP, consistent with previous studies, whereas Skírnisdóttir and Sorbe ${ }^{11}$,

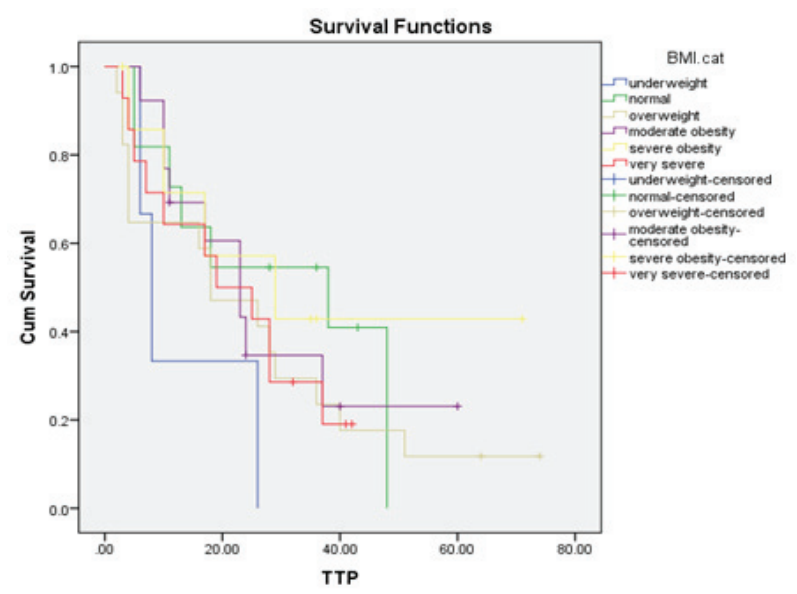

Figure. 4: Kaplan Meier curve showing time to progression of different BMI categories

Barrett et $a l^{17}$ and Hew et $a l^{18}$ found that TTP was identical in patients with elevated BMI and in those with normal BMI.

Regarding the pathological nature of the tumors and its relation to the BMI of the patients, our results showed an even distribution within the different BMI categories, which agrees with the results of Bae et $a l^{13}$ and Hew et al ${ }^{18}$

Similarly, we found no significant association between BMI and the tumor stage in epithelial ovarian cancer patients. This concurs with the results of Barrett et $a l^{17}$ and Hew et $a l^{18}$. In addition, no significant differences detected in the BMI according to parity, medical history, surgical optimality and initial CA-125, as reported by Bae et $a l^{13}$.

The known prognostic factors in epithelial ovarian cancer (e.g., platinum sensitivity) did not correlate with BMI, as previously reported ${ }^{18}$.

\section{CONCLUSIONS}

The prevalence of obesity among Egyptian patients with ovarian cancer is relatively high.

Although there is causal relationship between obesity and the development of epithelial ovarian cancers, no significant correlation obtained between BMI and OS and TTP among Egyptian patients. Similarly, there was no significant association between BMI and known prognostic factors in epithelial ovarian cancer.

The prognostic value of obesity remains a controversial issue with no consensus.

\section{REFERENCES}

1. Permuth-Wey J, Sellers TA. Epidemiology of ovarian cancer. Methods Mol Biol. 2009; 472:413-437.

2. Protani M, Nagle C, Webb P. obesity and ovarian cancer survival: a systematic review and meta-analysis. Cancer Prev Res (Phila). 2012; 5(7): 901-910. 
3. Australian Institute of Health and Welfare \& National Breast and Ovarian Cancer Centre. Ovarian cancer in Australia: an overview, 2010. Canberra, Australia: Australian Institute of Health and Welfare; 2010.

4. El-bolkainy N, Nouh A, Farahat I, et al. Pathology of cancer. Gynecologic malignancies. Cairo: Cairo press, 2013; pp. 277-297.

5. Cao Y, Ma J. Body mass index, prostate cancer-specific mortality, and biochemical recurrence: a systematic review and meta-analysis. Cancer Prev Res (Phila). 2011; 4(4):486-501.

6. Li AJ, Elmore RG, Pavelka JC, Karlan BY. Hyperandrogenism, mediated by obesity and receptor polymorphisms, promotes aggressive epithelial ovarian cancer biology. Gynecol Oncol 2007; 107(3):420-423.

7. World Health Organization. Body mass index classification. Available from: http://www.who.int/bmi/index. jsp?introPage=intro_3.html. Accessed: 6-October-2016.

8. Matthews KS, Straughn JM Jr, Kemper MK, Hoskins KE, Wang W, Rocconi RP. The effect of obesity on survival in patients with ovarian cancer. Gynecol Oncol. 2009; 112(2): 389-393.

9. Zhang M, Xie X, Lee AH, Binns CW, Holman CD. Body mass index in relation to ovarian cancer survival. Cancer Epidemiol Biomarkers Prev. 2005; 14(5): 1307-1310.

10. Moysich K, Baker J, Menezes R, et al. Usual adult body mass index is not predictive of ovarian cancer survival. Cancer Epidemiol Biomarkers Prev 2007; 16(3): 626-628.
11. Skírnisdóttir I, Sorbe B. Prognostic impact of body mass index and effect of overweight and obesity on surgical and adjuvant treatment in early-stage epithelial ovarian cancer. Int J Gynecol Cancer. 2008; 18 (2): 345-351.

12. Backes FJ, Nagel CI, Bussewitz E, Donner J, Hade E, Salani R. The impact of body weight on ovarian cancer outcomes. Int J Gynecol Cancer. 2011; 21(9): 1601-1605.

13. Bae HS, Kim HJ, Hong JH, Lee JK, Lee NW, Song JY. Obesity and epithelial ovarian cancer survival: a systematic review and meta-analysis. J Ovarian Res. 2014; 7:41.

14. Bae HS, Hong JH, Ki KD, et al. The effect of body mass index on survival in advanced epithelial ovarian cancer. J Korean Med Sci. 2014; 29(6): 793-797.

15. Tyler CP, Whiteman MK, Zapata LB, et al. The effect of body mass index and weight change on epithelial ovarian cancer survival in younger women: a long-term follow-up study. J Women's Health (Larchmt). 2012; 21(8): 865-871.

16. Nagle CM, Dixon SC, Jensen A, et al. Obesity and survival among women with ovarian cancer: results from the Ovarian Cancer Association Consortium. Br J Cancer. 2015; 113(5): 817-826.

17. Barrett SV, Paul J, Hay A, et al. Does body mass index affect progression-free or overall survival in patients with ovarian cancer? Results from SCOTROC I trial. Ann Oncol. 2008; 19(5): 898-902.

18. Hew KE, Bakhru A, Harrison E, et al. The Effect of Obesity on the Time to Recurrence in Ovarian Cancer: A Retrospective Study. Clinical Ovarian and Other Gynecologic Cancer. 2013; 6(1): 31-35. 